\title{
Curricula Construction and Reform Research on Database Principles and Applications Based on TOPCARES-CDIO
}

\author{
Hui Wang ${ }^{1, ~ a}$ and Yang $\mathrm{Yu}^{2, \mathrm{~b}}$ \\ ${ }^{1}$ No.1 Dongruan Road, Qingchengshan, Dujiangyan, Chengdu, Sichuan 611844, P. R. China \\ awanghui@nsu.edu.cn, byuyang@nsu.edu.cn
}

Keywords: Database; TOPCARES-CDIO; Teaching reform; Cooperative learning; Task-driven

\begin{abstract}
Database application, one of the fastest-growing technologies for computer science and technology development, has become an important basis and the core of computer application system and information system. This paper focuses on social requirements on database talent cultivation and studies the teaching model, teaching method and inter-curriculum correlation to improve teaching efficiency.
\end{abstract}

\section{Introduction}

Database, network and multimedia technology are the three major technologies of computer science and technical field. Database technology, an important foundation of computer application, can be widely applied. Therefore, Database Principles and Applications is deemed one of the primary courses in professional college education and the core curriculum for the whole major. The course requires students to acquire theoretical knowledge as soon as possible on the one hand and apply database theories and technologies to relevant field to solve practical problems on the other hand. Nevertheless, influenced by the traditional teaching model, there are still some problems in the course teaching, which can significantly hinder student's ability enhancement in application.

This paper studies the teaching status and existing problems of Database Principles and Applications. Referring to the ideas and characteristics of TOPCARES-CDIO engineering education, it conducts reform research on teaching content, teaching method, teaching model and inter-curriculum correlation so as to improve the teaching efficiency.

\section{Main Research Content}

Study on Teaching Design under TOPCARES-CDIO Model. According to the weaknesses of traditional teaching method and the current social needs of senior talent cultivation and giving consideration to the curriculum content and the characteristics of database technology of rapid development, extensive content and strong applicability, teachers should stress the role of student, teacher and theoretical knowledge and adopt project teaching and heuristic teaching with particular attention to practical teaching. Students should be offered the chance of practicing, independent study and innovation so as to improve the learning initiative and enthusiasm.

Study on Database Series Curriculum System and Inter-curriculum Correlation. Considering that college educator are faced with too many pedagogical tasks but are insufficient in teaching consistency, we propose the curriculum design concept of "precise localization and thorough transfusion" and conclude the core skills of computer science \& technology, software engineering, computer information management and other majors as software development technique (proficiency in a language) + database technique (proficiency in a database system). To design series and graded courses based on the two techniques makes students able to acquire specialized, refined and in-depth skills and meet the requirement of software development, information management and other duties (Different majors definitely should focus differently and design different curriculums).

To Carry out and Understand "Task-driven" Teaching in Database Principles and Applications. The core of "task-driven" teaching is: driven by the teaching task well designed by teachers, students fulfill the learning tasks through independent, collaborative, inquiry and 
discussion learning; in the process of problem solving, students learn relevant theoretical knowledge and have the learning ability trained. What's more important, they can have the learning interest, practical ability and collaboration competence increased; they learn the way of learning. Students are in an active position in task fulfillment all the time, while teachers are the organizer, tutor and guider. To carry out the "task-driven" teaching thoroughly, we tactically design the to-be-completed tasks and contain the desired knowledge and skills in them so that students are able to acquire the knowledge and skills in the task fulfillment. To be specific, the procedures include task assigning, task analyzing, student operation, exchange \& discussion, consolidation \& innovation and conclusion.

To Carry out and Understand "Case" Teaching in Database Principles and Applications. In the course teaching, we provide students with enriched cases developed with database modeling, database development and application system development and other aids to improve students' understanding of theoretical knowledge and the ability to operate. We set case situation and let students to study, explore, discover and experience knowledge under teachers' guidance. In this way, students learnt to collect, comprehend, analyze and judge knowledge information; they also learnt to acquire theoretical knowledge, use knowledge and solve problems. As a result, they have their ability to judge and create improved and the innovative thinking and practical skills cultivated.

To Carry out and Understand Cooperative Learning Model in Database Principles and Applications. The core of "task-driven" teaching is that students are asked to fulfill a task meticulously prepared by the teacher. The task is not supposed to be fulfilled by a student within a short time own his own. In fact, students are grouped to finish it as teams, which is a process of cooperated problem solving. Therefore, satisfactory teaching effects can be achieved only by combining "task-driven" teaching with small group teaching. We divide students into several groups according to their personal ability, prior knowledge and relevant factors. Team members cooperate with each other; they supervise and encourage each other and participate in the job proactively. To locate oneself in the team helps to reach satisfied learning and improved learning outcome and to accomplish the common objective of the team. In this process, learners can be liberated from teacher dependency and be able to collect useful data for the project task. Then, after independent comprehension and analysis, they discuss with other students in and out of the team to find different thinking ways and solutions, which is very helpful to knowledge learning and acquisition. "Cooperative learning model" significantly promotes the teaching of Database Principles and Applications, for it vivifies classroom climate, remarkably improves students' academic performance and significantly facilitates them developing good study habit. To overcome the inherent deficiencies of task-driven teaching, we combine it with other teaching models, such as case teaching, small group teaching and cooperation learning, so that they can be mutually perfected. The teaching efficiency proves to be satisfactory of adopting these models flexibly in different learning environments.

Investigative Study of Network Platform Design, Development and Application for Database Principles and Applications. The course team uses the existing network condition of the school to construct an investigative study platform for Database Principles and Applications, so that the classroom is extended through this public platform that grants online learning and exchanging and the interaction between teaching and learning of Database Principles and Applications.

\section{Curricula Construction Characteristics}

After years of construction, satisfactory hardware and software facilities have been provided for the teaching of Database Principles and Applications and the teaching effect has been well recognized by the public. The main characteristics include:

Distinctive teaching environment: The $3 \mathrm{~A}$ integrated virtual experiment \& training platform enables students to conduct 3D and interactive learning with mobile Internet terminals "anytime, anywhere and anyway".

Distinctive teaching method: The practice-oriented teaching method, emphasizing practicalness, is both fun and heuristic. We reliably guarantee talent cultivation for the school based on the 
understanding of inter-curriculum correlation and the integration of task-driven teaching and cooperative learning.

Distinctive teaching model: With reference to the eight major ability indicators of TOPCARES-CDIO, teachers are grouped and driven by project task to arouse students' learning interest and cultivate their team spirit.

Distinctive management: We have built an impeccable teaching information management platform and advanced management model and established sophisticated regulations and checking rules on course lecturing, course assessment, training course management, laboratory management and laboratory procedures.

The combination of our professional and rationally-structured faculties and multi-disciplinary knowledge has laid a solid foundation for the advancement, timeliness and practicability of the teaching content as well as advanced teaching methods.

\section{Conclusion}

We introduce TOPCARES-CDIO teaching model to each link of database teaching, which effectively arouses students' learning interest and trains their ability of problem solving. Meanwhile, focusing on the carrier of "task", we guide students in the learning and make the class interesting and practically enlightening, which may enhance their adaptive capacity to the career of software development. In classroom teaching, students are grouped to finish the assigned task with mutual cooperation, supervision and encouragement to acquire theoretical knowledge and practical skills. It helps them to improve their personal academic record, learning efficiency and accomplish the common objective of the team. What's more, they have their team-work ability strengthen in the process. To guarantee the smooth implementation and good teaching effects based on TOPCARES-CDIO model, we build a large number of teaching cases and analyze and enrich them from different aspect, which has provided a favorable case support to each link of daily teaching. After years of teaching research and reform, we have made remarkable achievements in the content, model and effect of the teaching of Database Principles and Applications.

\section{References}

[1] Wang Zhaohui, Jiang Xiaoding. Discussion on Teaching Reform of Network Database Curriculum. Computer and Modernization, 2007,12

[2] Wang Xianghui, Cui Wei, Xu Junli. Curriculum Reform Plan based on CDIO. Computer Education, 2011, 1.25

[3] Yao Zhengdong. Micro curriculum design strategies [J] China education of information technology, 2012, (11) PP .25-26.

[4] Zhang Yichun. Research and Thinking on the construction of micro course [J]. China education network, 2013, (3) pp. 28-30.

[5] Becca Nate (2013). Online teaching business school [EB / OL]. http: //www.ftchinese.com/story/001047178

[6] H. Y. Zhang, Y. G. Sun. The Exploration of the Teaching Reform of Electric Engineering Course based on the Excellent Plan [J]. China Electric Power Education, Jun. 2014: 62-65.

[7] S. R. Hu, H. Zhao. Practice and Exploration of the Certification of Engineering Education in Electronic Information Engineering Specialty $[\mathrm{J}]$. Journal of Wuhan University, 2012, 2:130-132.

[8] X. Z. Zhe, A. W. Han. The Present Situation, problems, and countermeasures of Higher Engineering Education in China [J]. 
[9] M. Li, Y. Xiao, J. X. Zhang, S. Xu, "Teaching team construction of electronic information based on Engineering Education Certification", Teaching and Cultivating People, Forum of Higher Education, Vol.5, 2015, pp.14-16.

[10]Engineering education accreditation standards, Engineering Education Certification Guide (2014 Version), published by Chinese Engineering Education Accreditation Association Secretariat, Mar. 2014.

[11]P. G. Li, X. D. Xu, G. S. Chen, "Analysis on the Problems and Reasons of Undergraduate Engineering Education Practice Teaching in China", Higher engineering education research. Vol. 3, 2012, pp.1-6.

[12] Yang Xiaohui. Research on the cultivation of entrepreneurship education and innovative talents in Colleges and universities of China [J]. China higher education research, 2015, 01:39-44.

[13]iang Hui, Ying Huiguang, Xu Xiaochang. Research Universities personalized innovative talents training mode $[\mathrm{J}]$. Journal of the National Institute of educational administration, 2015, 03:27-31. 